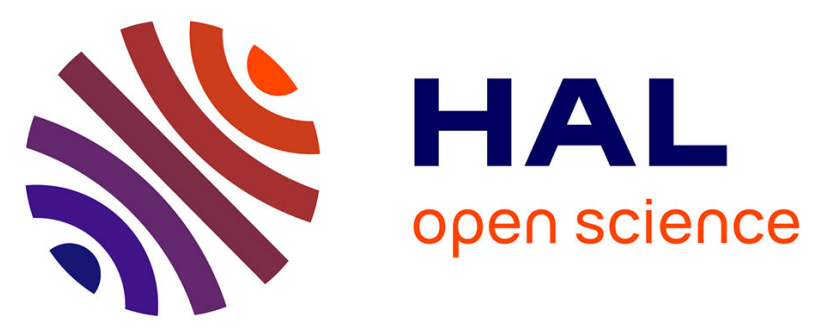

\title{
Optimization of microstructural evolution during laser cladding of Ni based powder on GCI glass molds
}

\author{
Fazati Bourahima, Anne-Laure Helbert, Vincent Ji, Michel Rege, Arnaud
}

Courteaux, Francois Brisset, Thierry Baudin

\section{To cite this version:}

Fazati Bourahima, Anne-Laure Helbert, Vincent Ji, Michel Rege, Arnaud Courteaux, et al.. Optimization of microstructural evolution during laser cladding of $\mathrm{Ni}$ based powder on GCI glass molds. Key Engineering Materials, 2019, Surface Modification Technologies, 813, pp.185-190. 10.4028/www.scientific.net/KEM.813.185 . hal-02360179

\section{HAL Id: hal-02360179 \\ https://hal.science/hal-02360179}

Submitted on 6 Dec 2019

HAL is a multi-disciplinary open access archive for the deposit and dissemination of scientific research documents, whether they are published or not. The documents may come from teaching and research institutions in France or abroad, or from public or private research centers.
L'archive ouverte pluridisciplinaire HAL, est destinée au dépôt et à la diffusion de documents scientifiques de niveau recherche, publiés ou non, émanant des établissements d'enseignement et de recherche français ou étrangers, des laboratoires publics ou privés. 


\title{
Optimization of microstructural evolution during laser cladding of $\mathrm{Ni}$ based powder on $\mathrm{GCl}$ glass molds
}

\author{
Fazati Bourahima $^{1,2, a}$, Anne-Laure Helbert 2,b ${ }^{2}$ Vincent $\mathrm{Ji}^{2, \mathrm{c}}$, Michel Rege ${ }^{1, \mathrm{~d}}$, \\ Arnaud Courteaux 1,2,e François Brisset 2,f , Thierry Baudin 2,g \\ ${ }^{1}$ Établissements CHPOLANSKY, 91462 Marcoussis, France \\ ${ }^{2}$ ICMMO, SP2M, Univ. Paris-Sud, Université Paris-Saclay, bât. 410, 91405 Orsay Cedex, France \\ a,*fazati.bourahima@chpolansky.fr, banne-laure.helbert@u-psud.fr, cvincent.ji@u-psud.fr, \\ dmichel.rege@chpolansky.fr, earnaud.courteaux@u-psud.fr, 'françois.brisset@u-psud.fr, \\ gthierry.baudin@u-psud.fr
}

Keywords: Laser cladding, HAZ, Ni-based powder, Cast-iron, ANOVA, Glass mold.

\begin{abstract}
In the glass industry, laser cladding is an innovative surfacing technique of depositing a layer of nickel to protect glass mold against corrosion, abrasion and thermal fatigue. This method (powder fusion by projection), well known in additive manufacturing represents a real technological leap for the glass industry. However, during laser cladding of Ni-based powder on gray cast iron, cracks can be observed for some process conditions. These cracks are often due to the Heat Affected Zone which creates structural stresses linked to the development of a martensitic structure in the ferritic matrix of the lamellar graphite cast iron. The aim of this work is to observe the impact of laser cladding (without substrate pre-heating usually used to limit cracking) on coating behavior but also on flake-graphite cast iron substrates. The microstructure and the mechanical properties were studied around the interface cladding/substrate. The impact of the processing parameters (power P, scanning speed $\mathrm{v}$ and powder feeding rate PFR was studied by using the ANOVA (ANalysis Of VAriance) technique. It has been observed that laser cladding on graphite cast iron without cracking is possible by limiting the linear energy induced by the process. Optimization of the processing parameters in order to obtain the industrial expected geometry of the coating has also been proposed.
\end{abstract}

\section{Introduction}

Laser cladding by the LMD (Laser Metal Deposition) technique is a surfacing method of producing high quality bonded coatings on a substrate in order to improve its thermal and mechanical resistance. In the glass industry, this process is used to protect glass mold against corrosion, abrasion and thermal fatigue [1]. During laser cladding of a Ni-based powder on Gray Cast Iron (GCI) with lamellar graphite, cracks can appear in the coating as well as in the substrate. The authors observed that the chemical composition can influence the cracking evolution of the deposit [2,3]. They discovered the presence of Cr-rich precipitates and the eutectic structure can increase the cracking susceptibility. Research has evidenced the influence of the processing parameters on cracking occurrence on the coating during laser cladding of a Ni-based alloy on ductile cast iron [4]. It described cracking caused by the increase in power and the scanning speed. Researchers [5] have observed Heat Affected Zones (HAZ) represented by needle-like martensite around graphite on GCI substrate after laser cladding [6]. Some authors have discovered crack propagation due to thermal stress concentration on the HAZ [7]. Some researchers have seen that the hardness in the HAZ reduces with a multilayer coating. In fact the martensitic structure transforms into tempered sorbite under the thermal influence after multilayer laser cladding [5]. This helped them to reduce the cracking behavior.

In the present paper, authors present the impact of the processing parameters on the microstructure of the deposit and the substrate. The laser parameter effect on the deposit geometry is also studied by using an ANOVA statistical method. It has been studied in previous work to predict the influence of processing parameters on dilution and porosity [8]. This experimental analysis, combined with the numerical one has finally made it possible to optimize the processing parameters in order to obtain a coating without cracks and with the required geometry. 


\section{Experimental and ANOVA method}

The composition of the Ni-based alloy powder with a grain size of $20-106 \mu \mathrm{m}$ is given as follows: Si 2.5, Fe 1, B 1.7, Cr 0.3, C 0.5, Mn 0.1 and Ni Bal. (wt\%). A GCI glassmold was used as substrate and has the following composition: Si 1-3, C 2.5-4, Mn 0.2-1, S 0.02-0.25, P 0.02-1 and Fe bal. (wt\%). Laser cladding was performed using a 4-kW continuous wave Nd: YAG of $1030 \mathrm{~nm}$ wavelength, 6-axis computerized numerical control platform and a 3-jet powder feed system. The energy was transmitted to a laser head by a $600 \mu \mathrm{m}$ diameter optical fiber, and then passed through a $150 \mathrm{~mm}$ focal length collimator and $220 \mathrm{~mm}$ focusing lens in the laser head. The processing parameters that must be considered are: the power $\mathrm{P}(1500$ to $2300 \mathrm{~W})$, the scanning speed $\mathrm{v}$ ( 2.5 to $10 \mathrm{~mm} / \mathrm{s}$ ) and the powder feeding rate PFR (24.5 to $32.5 \mathrm{~g} / \mathrm{min})$. The spot size was fixed at $4 \mathrm{~mm}$.

The powder was deposited onto a curvilinear substrate surface. Fig. 1a shows a glass mold after cladding. The section geometry after cladding is presented in Fig. 1b. The letter A represents the coating and the letter B the substrate. The industrial desired height $\mathrm{H}$ (taken along the powder projection axis) should be around $2.1 \mathrm{~mm}$ and the width $\mathrm{W} 4.5 \mathrm{~mm}$ in order to insure machining afterwards. The microstructure of the GCI substrate before cladding is given in Fig. 1c. It is composed of ferritic matrix $(\alpha)$ and lamellar graphite.
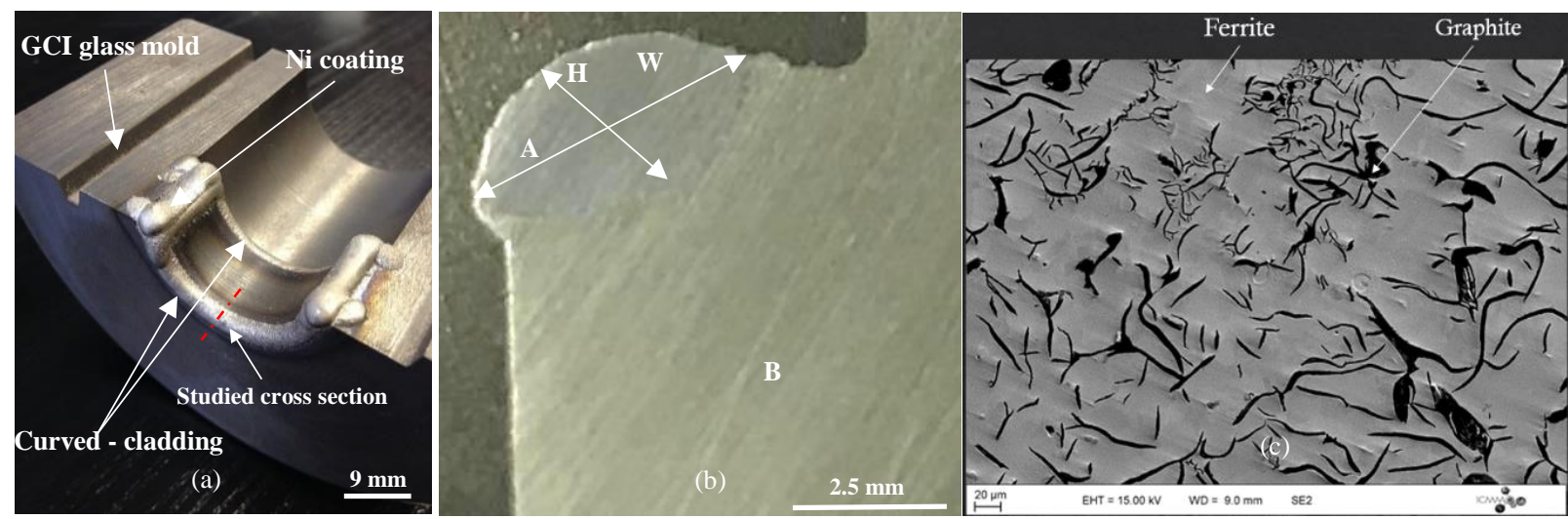

Fig. 1. (a) Mold after Ni laser cladding (b) curved section with the wanted final coating and (c) SEM of the gray cast iron with lamellar graphite before cladding

The sample (cross section-Fig. 1b) is polished with OPS suspension for EBSD (Electron BackScatter Diffraction), SEM (Scanning Electron Microscopy) and EDS (Energy Dispersive Spectroscopy) analyses. The microhardness of the cross section from the layer surface to the GCI substrate was measured using a Vickers hardness tester with a load of $0.01 \mathrm{kgf}$ and a dwell time of $15 \mathrm{~s}$.

The ANalysis of Variance (ANOVA) is a statistical method used to obtain the relationship between process parameters and output responses which are the coating height $\mathrm{H}$ and width $\mathrm{W}$. The range of the processing parameters for the studied samples for ANOVA analysis and microstructural characterization are given in table 1.

\begin{tabular}{|c|c|c|c|}
\hline & \multicolumn{3}{|c|}{ Factors } \\
\hline Parameters & $\mathrm{P}[\mathrm{W}]$ & $\mathrm{v}[\mathrm{mm} / \mathrm{s}]$ & $\operatorname{PFR}[\mathrm{g} / \mathrm{min}]$ \\
\hline Values & $1500-3000$ & $2.5-10$ & $24.5-32.5$ \\
\hline
\end{tabular}

Details of this technique are given in a previous published work [1]. 14 samples were used for this statistical study.

\section{Results and discussion}

The EBSD observation of the coating and the substrate according to the power $\mathrm{P}$ and the scanning speed $\mathrm{v}$ is given in Fig. 2. 


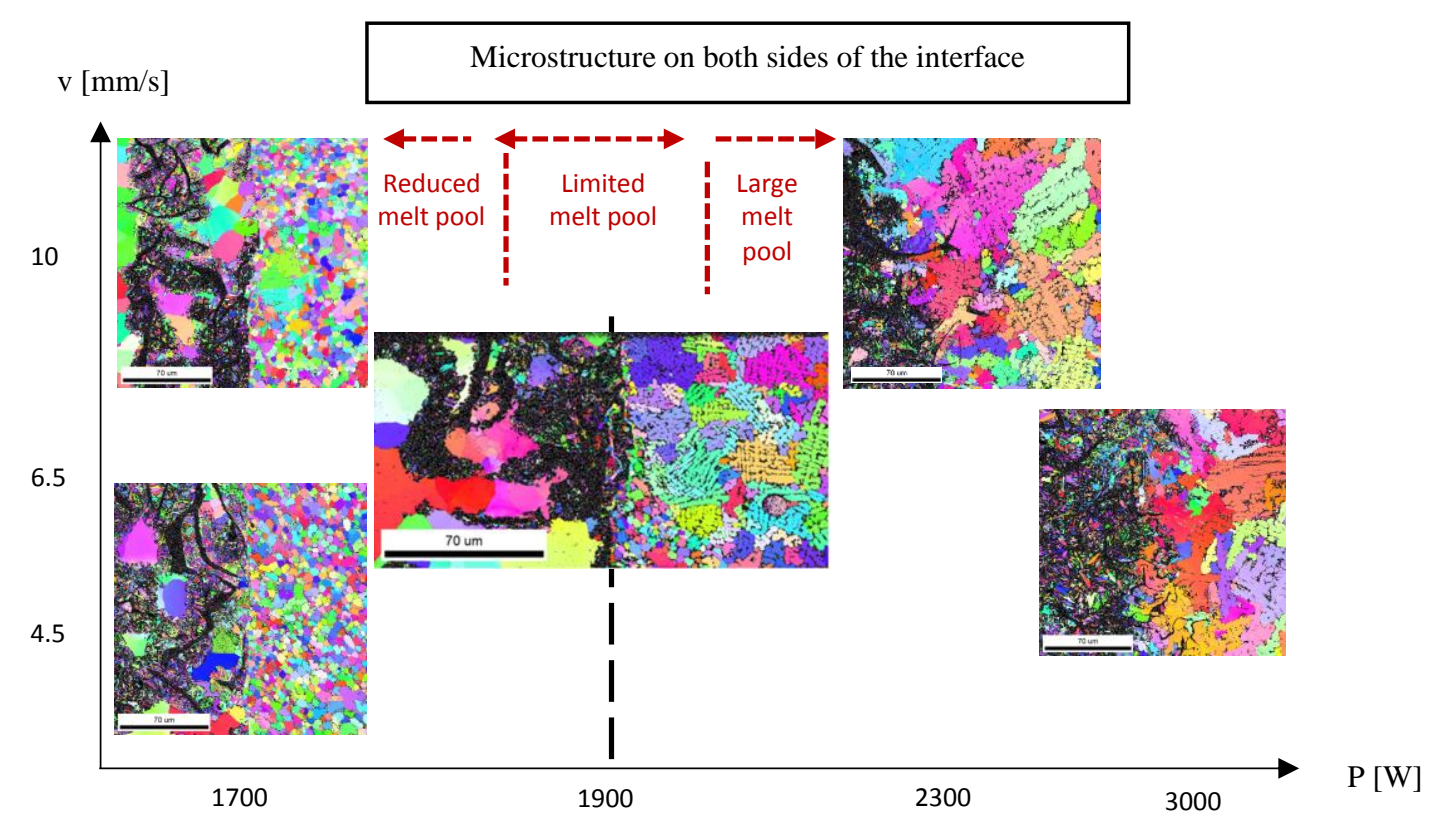

Fig. 2. EBSD analysis of the microstructural evolution on both sides of the interface coating/substrate according to $P$ and $v$

Two kinds of structure can be observed for Ni-coating close to the interface: an equiaxed structure when the power is under $1900 \mathrm{~W}$ and dendritic structure at higher power. The first structure is similar to ingot solidification: the equiaxed structure forms at a very high cooling rate during contact with a cold surface (the mold is at room temperature before cladding). The dendritic structure can be explained by a high absorption of the input energy by the substrate before Ni-deposition due to high laser power. This induces an increase of its temperature and allows the thermal gradient to decrease between the glass mold and the coating, leading to a dendritic structure of the coating.

Two kinds of structure can also be observed in the substrate close to the interface: a ferritic structure represented by random oriented grains and a needle-like martensite structure around graphite lamellar. The zone presenting the martensite corresponds to the HAZ. It can be seen that at low power, the ferritic phase is still present. But from a power of $2300 \mathrm{~W}$, the ferritic grains cannot be observed. Two kinds of martensite can be seen: the martensite formed after diffusion of carbon on the austenite and a very high cooling rate [5] (which is the case at a power under $1900 \mathrm{~W}$ ) and a martensite formed after fusion of the substrate and a very high cooling rate (power of $2300 \mathrm{~W}$ ). Far from the interface, the martensite is not observed. The influence of the PFR was not considered because its evolution is linked to the scanning speed evolution.

The formation of martensite is the consequence of carbon diffusion from the graphite into the austenitic matrix followed by a high cooling rate. It has been shown that the power and the speed have significant influence on the graphite morphology [9]. In order to understand the influence of $P$ and $\mathrm{v}$ on the HAZ, the diffusion distance $\mathrm{X}$ (distance from the lamellar graphite over which the martensite is observed) has been quantified close to the interface. $\mathrm{X}$ is proportional to $\sqrt{D t}$ with $\mathrm{D}$ the diffusion coefficient and the estimated diffusion time [10]. D follows the Arrhenius law:

$$
D=D_{0} \exp \left(\frac{-Q}{k T}\right)
$$

The carbon diffusion D0 coefficient in the CGI is $10-2 \mathrm{~cm}^{2} / \mathrm{s}$ (for the allotropic transformation at $1185 \mathrm{~K})$. Q is the activation energy $(80.3 \mathrm{~kJ} . \mathrm{mol}-1)$, $\mathrm{k}$ the gas constant (equal to 8,314 J.mol-1.K1) and $\mathrm{T}$ the constant temperature and equal to $1185 \mathrm{~K}$ (temperature of the allotropic transformation). The experimental and calculated $X$ evolutions according to $\mathrm{P} / \mathrm{v}$ (linear energy in $\mathrm{J} / \mathrm{mm}$ ) are given in Fig 3. 


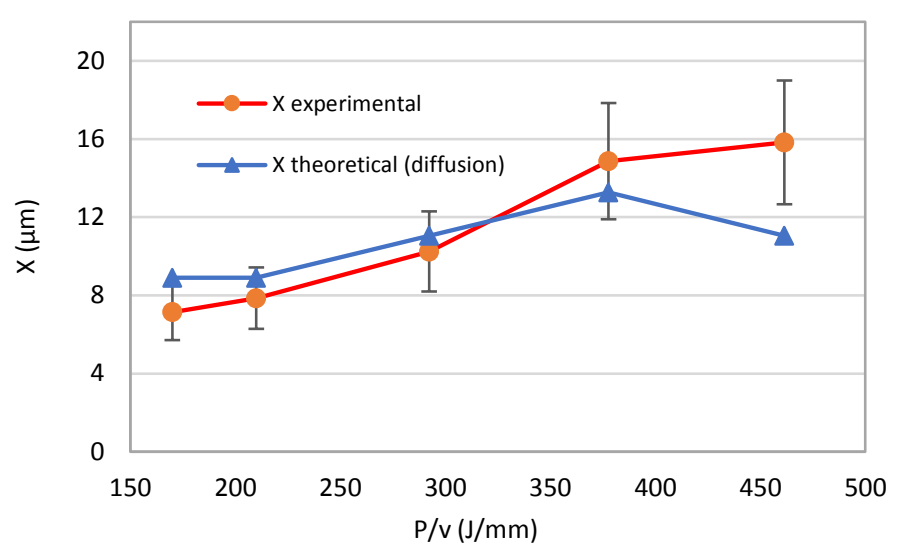

Fig. 3. Diffusion length X around the lamellar graphite according to P/v. Comparison between experimental and calculated X (Eq. 1)

Fig. 3 shows that $\mathrm{X}$ increases with $\mathrm{P} / \mathrm{v}$. Calculated and experimental $\mathrm{X}$ values are also in good agreement. For the low values of $\mathrm{P} / \mathrm{v}$, the calculation overestimates $\mathrm{X}$ because the substrate has probably not reached $1185 \mathrm{~K}$ yet. For high values of $\mathrm{P} / \mathrm{v}$, the calculated $\mathrm{X}$ is underestimated because the martensite is probably obtained from the austenite at a temperature higher than $1185 \mathrm{~K}$. Indeed, it is worth noting that for the last point, a good estimation of X could be obtained for a temperature of $1293 \mathrm{~K}$.

The presence of HAZ can induce cracks due to high hardness. So, microhardness measurements were performed on two samples presenting all the microstructures described in Fig. 2: martensite around lamellar graphite, equiaxed small grains, dendritic structure and ferrite. The result is shown in Fig. 4. It can be noted that for both samples, the microhardness of the ferrite is not higher than $180 \mathrm{HV}$. The equiaxed grains present a microhardness of $350 \mathrm{HV}$, which is almost equivalent to the dendritic structure at the interface for sample 2. Dendrite hardness is similar whether the dendrites are close or far from the coating/substrate interface. In the HAZ, the microhardness of the martensite reaches up to $780 \mathrm{HV}$. This unstable phase is of a high hardness, which can lead to a cracking behavior as proved by some authors [5]. In order to provide a crack-free coating, it is advisable to limit the HAZ by decreasing the laser input power (under $2300 \mathrm{~W}$ for example to maintain the presence of ferrite grains and limit the molten bath) or increasing the scanning speed. In fact, the HAZ size evolves with $\mathrm{X}$ length, because they are both linked to diffusion mechanisms, and can be restricted if $\mathrm{P} / \mathrm{v}$ remains as weak as possible. The lower acceptable value of $\mathrm{P} / \mathrm{v}$ will be driven by the coating geometry constraints. The following ANOVA statistical study will thus identify these parameters in accordance with industrial requirements.

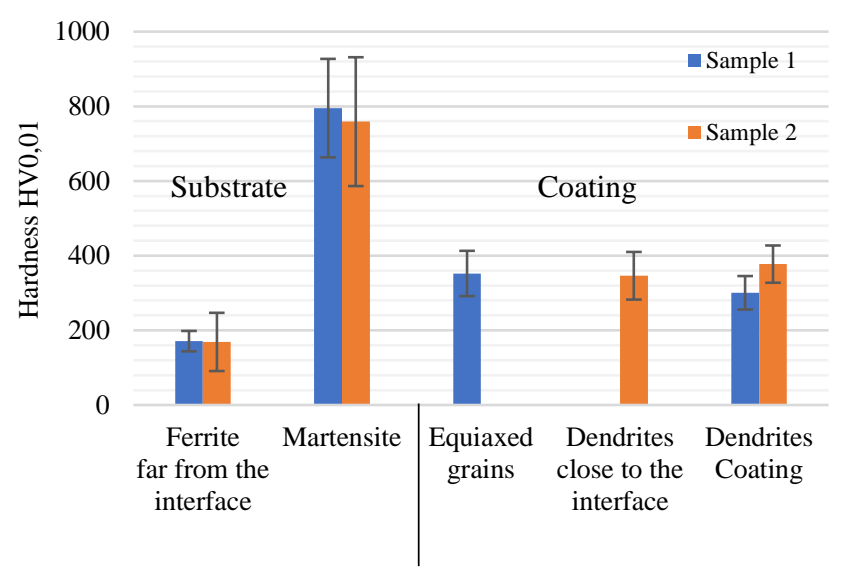

Fig. 4. Microhardness of different phases after laser cladding for sample 1 and sample 2

The results presented above lead to the conclusion that diminishing $\mathrm{P} / \mathrm{v}$ ratio could be a good way to limit HAZ and thus cracking. In order to limit this HAZ and to respect the coating geometry 
( $\mathrm{H}$ and $\mathrm{W})$, An ANOVA analysis has been conducted. The equations of both responses $(\mathrm{H}$ and $\mathrm{W})$ as a function of the processing parameters are given (Eq. 2 and 3). The relative errors are estimated under $5 \%$ for $\mathrm{W}$ and $17 \%$ for $\mathrm{H}$. The relative error allows a comparison of the predicted and the measured values.

$$
\begin{gathered}
H=26,57-1,34.10^{-4} P-1,07 P F R-2,39 v+3,31 \cdot 10^{-5} P . P F R+5,64 \cdot 10^{-4} P . v+0,07 P F R . v \\
+1,08 \cdot 10^{-6} P^{2}+9,25 \cdot 10^{-3} P F R+0,07 v^{2} \\
\text { and } \\
W=77,47-0,01 P-3,77 P F R-2,42 v+2,14.10^{-4} P . P F R-1,08.10^{-3} P . v+0,14 P F R . v \\
+3,59 \cdot 10^{-6} P^{2}+0,04 P F R+0,03 v^{2}
\end{gathered}
$$

An optimization of the process parameters using ANOVA calculation to obtain the expected coating geometry is then presented Fig. 5. Fig. 5 shows that scanning speed is the most influential parameter on height. Increasing $\mathrm{v}$ leads to a decrease in height which can be explained by a powder quantity that decreases at high speed. It is difficult to describe the impact of the PFR because the range of values is not large enough to detect significant variations. The range of desired width is within the blue lines and the height within the pink ones. The optimization areas are given in discontinuous yellow lines. An example of parameter combination making it possible to obtain the desired coating geometry and to limit martensite formation (HAZ) could be $\mathrm{P}=1900 \mathrm{~W}, \mathrm{v}=7.5$ $\mathrm{mm} / \mathrm{s}$ and $\mathrm{PFR}=28.5 \mathrm{~g} / \mathrm{min}$.

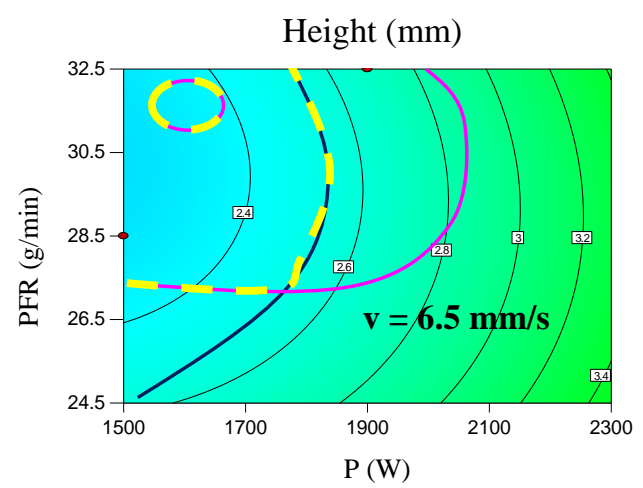

(a)

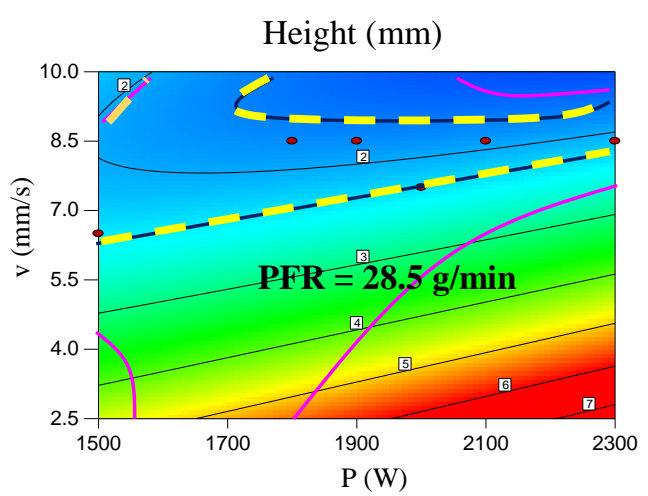

(b)

Height (mm)

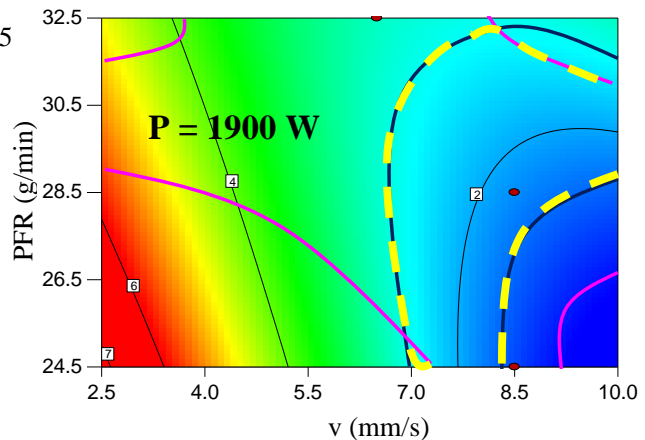

(c)

Fig. 5. Optimization of the processing parameters. Evolution of $H$ according to (a) PFR and $P$ for a fixed value of $v$ at $6.5 \mathrm{~mm} / \mathrm{s}$, (b) $v$ and $P$ for a fixed value of PFR at $28.5 \mathrm{~g} / \mathrm{min}$ and $(c) P F R$ and $v$ for a fixed value of $P$ fixed at $1900 \mathrm{~W}$. Taking into account the $W$ evolution (in pink lines), the optimized parameters are given in discontinuous yellow lines

\section{Conclusion}


The microstructure and mechanical performance of Ni-based alloy applied to Gray Cast Iron by laser cladding was studied. Optimization of process parameters was provided using the ANOVA method. The conclusions can be listed as follows:

- A Ni-based alloy was successfully deposited using laser cladding on GCI by respecting the desired coating geometry.

- The coating microstructure is not sensitive to the process parameters. Ni-dendrite structures develop both close to the substrate and in the deposit bulk.

- In the iron substrate, martensite is easily formed, and its quantity is related to the linear energy $P / v$.

- The high hardness of the martensite phase was measured at approximately $780 \mathrm{HV}$. This phase development can induce cracks in the substrate and must be limited by choosing appropriate $P$ and $\mathrm{v}$ values (limiting $P / v$ ratio). Also, the coating hardness is not sensitive to the microstructure (equiaxed grains or dendrites) and thus, to the process parameters.

- The ANOVA method allowed us to predict the influence of the parameters on the coating geometry. Moreover, industrial sets of parameters have been identified to guarantee both a limited HAZ and the expected coating geometry.

\section{References}

[1] F. Bourahima, A.L. Helbert, M. Rege, V. Ji, D. Solas, T. Baudin, Laser cladding of Ni based powder on a $\mathrm{Cu}-\mathrm{Ni}-\mathrm{Al}$ glassmold: Influence of the process parameters on bonding quality and coating geometry, J. Alloys Compd. 771 (2018) 1018-1028.

[2] I. Hemmati, V. Ocelík, J.T.M. De Hosson, Effects of the alloy composition on phase constitution and properties of laser deposited Ni-Cr-B-Si coatings, Phys. Procedia. 41 (2013) 302-311.

[3] J. Yu, B. Song, Friction and wear behavior of a Ni-based alloy coating fabricated using a multistep induction cladding technique, Results Phys. 11 (2018) 105-111.

[4] Q.D. Li, J.C. Liu, Effect of process variables on the crack in laser cladded Ni-alloy on ductile cast iron, High-Power Lasers Appl. V. 7843 (2010) 1-11.

[5] H. Liu, J. Hao, Z. Han, G. Yu, X. He, H. Yang, Microstructural evolution and bonding characteristic in multi-layer laser cladding of $\mathrm{NiCoCr}$ alloy on compacted graphite cast iron, J. Mater. Process. Technol. 232 (2016) 153-164.

[6] Y. Liu, X. Zhan, P. Yi, T. Liu, B. Liu, Q. Wu, Research on the transformation mechanism of graphite phase and microstructure in the heated region of gray cast iron by laser cladding, Opt. Laser Technol. 100 (2018) 79-86.

[7] T. Xin, L. Fu-hai, L. Min, D. Ming-jiang, Z. Hong, Thermal fatigue resistance of non-smooth cast iron treated by laser cladding with different self-fluxing alloys, Opt. Laser Technol. 42 (2010) 1154-1161.

[8] L. Reddy, S.P. Preston, P.H. Shipway, C. Davis, T. Hussain, Process parameter optimisation of laser clad iron based alloy: Predictive models of deposition efficiency, porosity and dilution, Surf. Coatings Technol. 349 (2018) 198-207.

[9] P. Yi, X. Zhan, Q. He, Y. Liu, P. Xu, P. Xiao, D. Jia, Influence of laser parameters on graphite morphology in the bonding zone and process optimization in gray cast iron laser cladding, Opt. Laser Technol. 109 (2019) 480-487.

[10] J. Philibert, A. Vignes, Y. Bréchet, P. Combrade, La diffusion, in: MASSON (Ed.), Métallurgie Du Minerai Au Matériau, MASSON, 1998: pp. 399-411. 